\title{
The Model of Customer Empowerment in the Field of Renewable Energy: A Case of Tunisian Consumers
}

\author{
Chiraz Rouissi $^{1} \&$ Fatma Letaif $^{2}$ \\ ${ }^{1}$ Assistant Professor, Jeddah University, Saudi Arabia \\ ${ }^{2} \mathrm{PhD}$ Student, Faculty of Economics and Management, Tunisia \\ Correspondence: Chiraz Rouissi, Assistant Professor, Jeddah University, Saudi Arabia. E-mail: \\ charrouissi@yahoo.fr
}

Received: December 18, 2021

Accepted: February 5, $2022 \quad$ Online Published: February 17, 2022

doi:10.5539/ijms.v14n1p7

URL: https://doi.org/10.5539/ijms.v14n1p7

\begin{abstract}
This awakening of consciousness on the part of today's consumers has given rise to the concept of consumer empowerment which states that the current consumer has become a stakeholder and influence in their purchasing decisions. Thus, the current consumer is asking deeper questions, such as environmental rights, animal rights, the rights of future generations, and the rights of the community. This paper proposes an explanatory model of empowerment emanating from new Information and Communication Technologies (ICTs), which participated in the crystallization of the concept by giving more power and control to Tunisian consumers. A model was developed from qualitative research based on individual interviews to explore in-depth the world of Renewable Energies Consumption (REC).
\end{abstract}

Keywords: empowerment, consumers, renewable energy, Tunisia

\section{Introduction}

With the advent of the Internet, which transformed information scarcity into information democracy (Sawhney \& Kotler, 2001) or transparency (Deshpande, 2002), researchers began to discuss the difficulties of understanding and controlling consumers with traditional marketing approaches.

Today's consumers feel less dependent on businesses, and enjoy more freedom (Jordan, 1999; Wolfinbarger \& Gilly, 2001) and control (Wolfinbarger \& Gilly, 2001; Kucuk \& Krishnamurthy, 2007) on their operations and business relations. Subsequently, companies are now in the duty to invest in renewable energies not only because the current consumer is aware of the importance of environmental protection, but also because these energies represent, without a doubt, a profitable investment. This is the subject of investigation in this article. The approach is exploratory, and the objective is therefore to understand the role played by consumer empowerment in the transition of ethical consumption and its influence on the adoption of renewable energies (Nawaz et al., 2021).

Does consumer empowerment push consumers to get involved in a social responsibility approach by using renewable energies? The first part presents the emergence of the phenomenon of consumer empowerment in the field of renewable energies; the second part exposes the behavior of consumers with the rise of consumerism movements. Finally, the third part discusses the managerial consequences of consumer empowerment in an ethical context.

\section{Literature Review}

Consumer empowerment can be defined as a subjective positive state evoked by increased control (Wathieu et al., 2002). Empowerment represents a positive state that results from control but does not represent control per se. Thus, the ability of consumers to have control over their own choices has been considered the keystone of the notion of empowerment (Wathieu et al., 2002). Whether applied to employees or customers, empowerment is synonymous with takeover (Werner, 1992). Thus, consumers with more knowledge are likely to feel more powerful in the market (Foucault, 1972; Thio et al., 2021). Indeed, consumer empowerment increases consumer value by providing them with wider access to information sources and decision-making (Turnquist, 2004). It's about helping consumers to choose what they want, when they want, on their terms. Therefore, consumer empowerment is based on a higher waiting threshold. This effect is implicit in the description of "new 
consumers" (Traulsen \& Noerreslet, 2004) and consumers are becoming increasingly demanding (Koco, 2000). Thus, the adequate level of consumer expectation is supported to be dynamic and more changing than their desired service expectations (Parasuraman et al., 1991). As a result, it can be seen that consumer empowerment is beneficial to the consumer (Goldsmith, 2005; Henry, 2005; Pitt et al., 2002; Newell, 2003; Arsy, 2021). In addition, the notion of empowerment is equated by several authors with consumer-centric marketing strategies. This is because consumer-centric marketing strategies focus on creating value by providing customers with the service they need. This value creation is achieved through a combination of technologies focused on various processes. These processes allow customers to be the focus of all activities, helping them design product features or choosing the most appropriate level and type of service and informing them about new products of interest (Paulin et al., 2000). It is a customer-centric strategy (Rangaswamy, 2001), which is the meaning of consumer empowerment, as it seeks to give control to consumers (Parasuramam, 1997).

Today's consumers are often seen as co-creators of value (Senge \& Carsted, 2003). Indeed, this establishment of consumer culture has been accompanied by a growing concern among many consumers about the impact of their consumption levels in general on the natural environment as well as on their well-being and that of others (Diamantopoulos et al., 2003; Strong, 1996; Shaw \& Clarke, 1999). An increasing number of people seek to act beyond their immediate interests as consumers and to examine the impact of their choices on society at large (Doane, 2001). In this context, the notion of consumer empowerment has contributed to the emergence of consumer citizenship (Lang \& Gabriel, 2005; Laksito \& Yudiarta, 2021). Several examples illustrate the pressure on companies to comply with ethical rules. Similarly, we can cite the boycott of Shell in 1995 because of their oil platform Brent Spar (Grolin, 1998), the calls strongly denouncing genetically modified foods (Gaskell, 2000), or the boycott against Nike in response to child labor (Tomolillo \& Shaw, 2003). The fact that large multinationals are confronted with consumers enjoying increasing power by crystallizing the notion of empowerment (Clouder \& Harrison, 2005) has pushed organizations such as Shell to solve the problem after suffering a temporary loss of sales especially in Germany (Grolin, 1998).

Ultimately, it can be concluded that the current consumer enjoying a high level of empowerment is no longer obsessed with purely economic choices but now integrates other discriminating criteria, essentially ecological and social, into his choices. Consumption is no longer an ephemeral act, but rather a long-term action that must preserve the interests of future generations. Non-renewable sources of energy, regardless of estimates of global reserves, are, after all, only a capital stock, while renewable sources are a flow, a continuous income. Thus, it seems natural that day by day, people must rely on this potential and avoid limiting themselves to using energy capital only in an emergency (Boamah, 2021). Similarly, faced with the question of justice and the equitable distribution of natural resources in the world (Maple, 1989) and in the face of an awakening of consciousness among populations, there are more and more people who encourage the use and development of renewable energies (Devine \& Wright, 2005). Indeed, the latter makes it possible to reduce the existing gap between countries and help to establish the notions of equality and equitable distribution of benefits (CRC, 1998) so that developing countries that are generally hampered by the lack of natural resources can benefit from these new forms of energy (Angelo, 2021). For example, Nepal has a great untapped hydropower potential, matching the hydroelectric capacity of Canada, the United States, and Mexico. According to the International Energy Agency's (IEA) scenario, global demand for renewables is expected to grow at a compound average annual growth rate of 7.3\% between 2007 and 2030. In the United States, one of the countries that consume the most energy, renewables accounted for about $8 \%$ of total national energy demand in 2009 and renewable energy consumption increased by $8 \%$ between 2008 and 2009 .

Again, and as an example, the CEO of the industrial company CSO indicated that a \$20 million investment in energy efficiency was repaid in less than three years and the company saved $\$ 6.2$ million in electricity bills. Still, many companies have begun to adopt an appropriate citizenship approach with the new culture and values of consumers such as several cafes that offer a discount for customers who bring their cups or IT companies that have a take-back and recycling program (Kurland \& Zell, 2011). Moreover, it is noted that this enthusiasm for sustainable development and in particular renewable energies has flourished in Germany since the oil crisis of 1973 demonstrating the dependence on energy imports (Pulczynski, 1991). The rise of consumer empowerment has been accompanied by the emergence of several new concepts that have come to meet the new requirements.

Thus, green marketing, for example, takes advantage of customers' willingness to buy, and sometimes pay more for products that offer environmental benefits. In this sense, several studies have reported that a large number of customers (40-70\%) are willing to pay a surplus of 5-15\% for "green" products, including renewable energies (Baugh et al., 1994; Farhar \& Houston, 1996, Nakarado, 1996; Farhar, 1994; Ottman, 1993). Thus, several empirical studies have shown that several customers have expressed their willingness to pay more for renewable 
energies (Rader \& Norgaard, 1996). As a result, proponents of green energy commercialization argue that they have the potential to create a renewable energy market that is not dependent on government policies (Nakarado, 1996; Quartey-Papafio et al., 2021).

This idea is economically defensible, as several polls indicate a large latent demand for renewable energy worldwide (Serchuk \& Miller, 1996). This is mainly due to consumers' awareness of their environment and the merits of renewable energy (Harrison, 1997).

Indeed, renewable energy provides various undisputed environmental benefits over other forms of energy (Proops et al., 1996, Chupka \& Howarth, 1992). Thus, a customer who buys renewable energies is not able to benefit alone, but this choice will generate a virtuous circle in his region, his country, and even on an international scale.

Again, the use and development of renewable energies ensure the reduction of fuel prices and the risk of supply disruption (Hoff \& Herig, 1996). Finally, the consumer empowerment that has been accompanied by the proliferation of "green" products more expensive than regular products (Wasik, 1996; Ottman, 1993; Cairncross, 1992; Vandermerwe \& Oliff, 1990; Simon, 1992; Shah et al., 2021) is proof that today's consumer has reached a threshold of accountability that guarantees the development of renewable energies independently of government efforts. As a result, all firms can respond effectively to this new dominant paradigm.

\section{The Ethical Economics of Renewable Energies}

\subsection{Germany: A Model to Follow}

The German discourse on renewable energy began during the 1973 oil crisis, which highlighted the dependence of some countries on the international supply of energy (Pulczynski, 1991).

In 1980, scientists from the Institute of Applied Ecology in Fribourg published a work featuring alternative energy scenarios (Krause et al., 1980), with a particular focus on energy conservation. Moreover, the wind energy sector is a very good example of technological evolution and the emergence of the renewable energy industry in Germany. But this success of the German business model in terms of renewable energy is also due to the efforts made by the state. Indeed, government projects to support renewable energy in Germany began in 1974 with the Federal Government's Framework Program for Energy Research (Pulczynski, 1991).

A large number of federal programs dispersed regional and local supports were available to support investments in renewable energy generation through grants, tax incentives, or subsidized loans (Grotz, 2002). Nevertheless, all these efforts made by the State and the various stakeholders promoted the renewable energy sector emanated from the will of the population and in particular of consumers. Indeed, renewable energies, which have always received various forms of political support (Wiser \& Pickle, 1997), have become, today, a popular demand (Nakarado, 1996), so some authors even suggest that public policies that support these technologies will no longer be needed (Bohi \& Montgomery, 1997). Indeed, Germany is probably the country in Europe and the world that is the most advanced in the transition of energy, in the exit from a centralized energy system and dependent on resources of fossil origins.

\subsection{Corporate Social Responsibility: Imposed Requirements or Strategic Choice}

Faced with the awakening of consumer consciousness and especially with the rise of consumerism movements, companies are imposing strict regulations on pollution and environmental protection. This no longer even represents a choice but a requirement under penalty of being sanctioned and boycotted by its customers. Thus, various companies invest in environmental protection not out of concern for future generations but rather to improve their brand image. In addition, other companies have even specialized in this new environmental sector and have managed to raise millions of dollars in revenue.

\subsubsection{Boycott the Lethal Weapon of Consumers}

Historically, the boycott is attributed to several spectacular successes. For example, Wolman (1916) and Laidler (1963) decry how boycott was key to the success of labor movements in the United States at the turn of the twentieth century. The boycott organized by Gandhi as part of a strategy of non-violent action resulted in Indian independence in 1947 (Bondurant, 1965).

Rosa Parks' refusal to give up her seat on a bus to a white man triggered the Montgomery bus boycott in 1955, a boycott that almost caused the bus company to go bankrupt because it was supported by more than 90 percent of blacks. Similarly, a boycott campaign against ExxonMobil, organized in the face of its opposition to climate change theories, has led to the loss of more than a million British motorists according to a study conducted by the MORI Institute, as he pointed out high levels of consumer interest in corporate responsibility in the 
Millennium Survey, administered to 25,000 consumers in 23 countries (Environics, 1999): Worldwide, 40\% of the 25,000 respondents thought last year about punishing a specific company perceived as not being socially responsible. Meanwhile, consumers were all equally likely to "reward" a society perceived as socially responsible. The reason for all these and other actions is that today's consumer wants to buy products for themselves while ensuring the sustainability of the outside world (Harrison, Newholm, \& Shaw, 2005). For this, data from various surveys suggest that up to $90 \%$ of consumers consider the factor of corporate responsibility in their purchases (Vogel, 2005). It follows from the above that the consumer market has become lucrative and represents a rather interesting niche.

\subsubsection{The Ethical of Economics}

Various associations have produced reports on the profitability of corporate responsibility actions, such as "Business for Social Responsibility", "The World Business Council for Sustainable Development" and "The International Business Leaders Forum". These reports highlight the benefits of citizen actions.

Even governments produce business cases on the subject of citizen actions such as the UK Department of Trade and Industry which supports the idea that corporate social responsibility represents not only benefits for society but also the business community. Indeed, various studies have noted that the most responsible companies are the most profitable (Vogel, 2005).

This is undoubtedly due to the change in the structure of current consumer behavior. Moreover, Vogel (2005) mentions a European study in 2004 where they find that $75 \%$ of respondents indicated that they would modify their purchases because of social and environmental criteria. Recent data and examples from the UK are also suggestive of growing support for ethical consumption. For example, fair trade sales doubled in the UK between 2003 and 2005, from $£ 92.3$ million to $£ 195$ million (Grande, 2007). Still, the Ethical Consumerism Report in 2005 , published a British survey produced by The Co-operative Bank, which found that $54 \%$ of respondents in 2004 agree with the statement: "As a consumer, I can identify socially responsible companies." Only $17 \%$ disagreed with the statement (the figures were $51 \%$ and $26 \%$, respectively, in 1999). The same report identifies nearly $£ 26$ billion in "ethical spending" in 2004 (up 15.4\% from 2003), including $£ 4$ billion in food spending (including organic and vegetarian products), $£ 2.6$ billion in "green homes" (e.g., the energy efficiency of electrical appliances), $£ 1.6$ billion in travel and transport, $£ 7$ billion in personal items (e.g., clothing), and $£ 10.6$ billion in ethical finance (e.g., ethical investments). The calculations include boycotts. Also, the ethical brand image was very important for the building of the reputation of all firms. Like what the company Innocent Drinks, leader of the smoothie market in the United Kingdom (2005) with more than $60 \%$ market share and the $£ 100$ million plays its major asset via its ethical image by setting itself as a vision "we want to leave things a little better than we find them." it claims to make $100 \%$ natural products that are $100 \%$ good for people" (its smoothies are not concentrate-based).

The Toyota Prius, the first mass producer of gas (gasoline) and hybrid electric vehicle, was introduced in Japan in 1997 and entered the American market in 2000. Very quickly, it acquired a loyal clientele among environmentally conscious consumers.

In January 2007, Marks and Spencer announced a five-year program to become the UK's most social-environmental retailer, committing to making the group's carbon neutral and disposal of all waste in landfills by 2014 (Rigby \& Harvey, 2007). In addition, Wal-Mart, the world's largest retailer, also announced that it was taking its "first steps towards sustainability" by reducing the energy needs of all existing stores by $20 \%$ by 2010 and reducing total carbon dioxide emissions by $25 \%$ by 2013 . Ultimately, we must conclude with a glowing reality that sustainability now plays an important role and mainstream of current consumption (Rigby, Harvey, \& Crooks, 2007). However, what about the Tunisian context? Is the Tunisian consumer ready to accept ethical consumption? Is he willing to pay more for eco-friendly products? Is it conscientious of the importance of renewable energies in the development of the economy?

\section{Methodology of the Article}

Data collection: Semi-directive interview method

This is exploratory research that has used the semi-directive individual interview as a method of collection given great flexibility and the wealth of information it can generate (Huberman \& Miles, 1991). With an average duration between 30 and 45 minutes (individual interviews), all interviews took place over four months, from March 2021 to June 2021.

The semi-structured interviews were conducted as follows: they were 12 individual interviews with people aged between 35 and 55, with a diploma of bachelor's degree or master's degree. The interview guide was divided 
into four parts: the first concerns the empowerment of the Tunisian consumer, the second applies to ethical consumption, the third applies to renewable energies and socially responsible companies and the last part concerns the profile of the consumer.

\section{Proposal of the Conceptual Model}

Thus, to check whether the entire Tunisian population is finally ready for the adoption of these renewable energies or just an elite is to understand the relationships between the concepts identified in the proposed model. Thus, we arrive at the conceptual model:

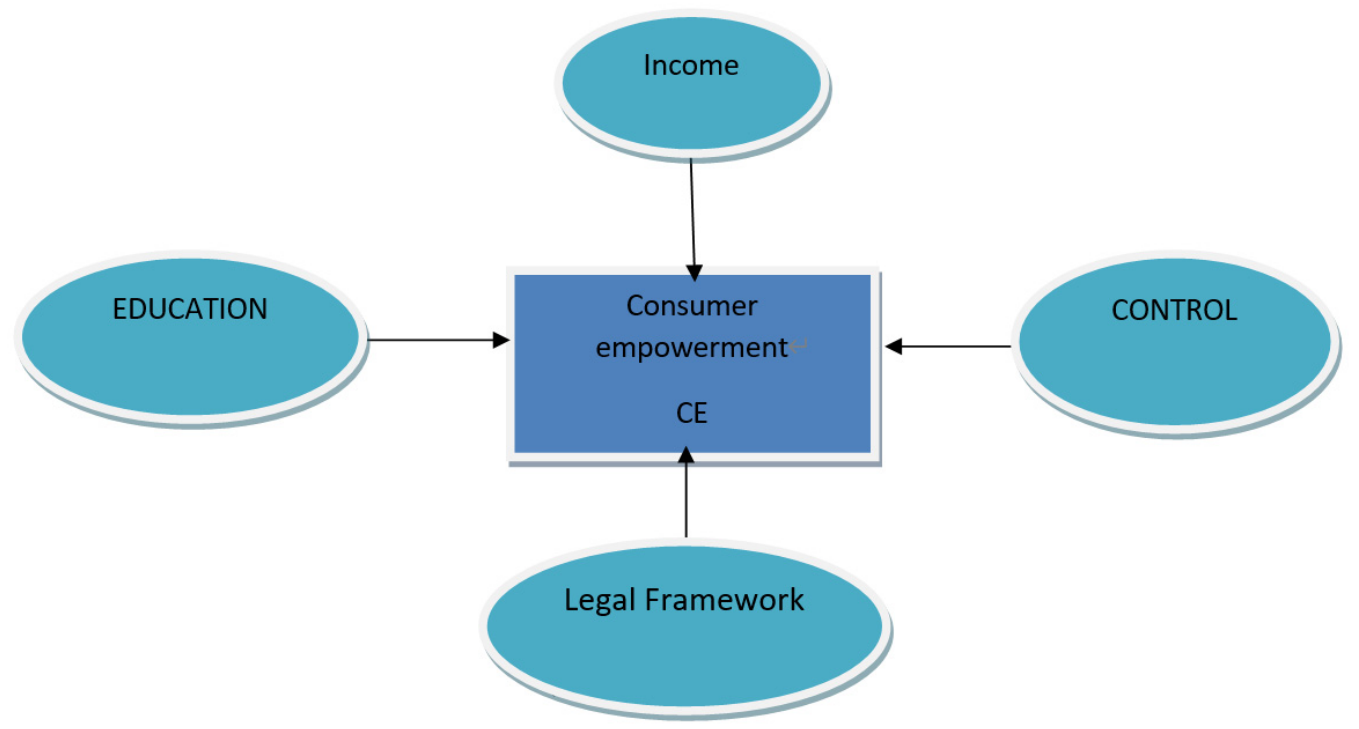

Figure 1. Conceptual model

\subsection{Presentation of the Concepts}

Here is a brief overview of our concepts in the following:

- The Education: This concept relates to the levels of education of our respondents, i.e., whether they have a secondary, primary, or university level. The level of education is generally considered whether in academic or professional research as a good indicator of the level of awakening consciousness of the individual.

- The Income: Relates to the socio-professional category of the individual and his salary. This is one of the most discriminating criteria in market segmentation and company categorization. It is noted that in general people with a high salary are the most concerned about environmental economic problems because they are already satisfied with their primary needs (physiological, security, Maslow pyramid, etc.).

- The Legal Framework: This is the set of legal rules and laws promulgated by the State to regulate, organize, and above all encourage the market relating to renewable energies.

- The Consumer Empowerment: This concept brings together the notions of power, the consumer's controlling force as well as his spirit of citizenship and socially responsible consumer towards his environment.

\subsection{Explanation of the Links Between Research Concepts}

Through the qualitative study that we propose, we will try to interpret the possibility of the existence of certain links without, of course, deciding on the accuracy of these relationships without resorting to a quantitative study. Our interview guide is structured in such a way as to see, at first glance, whether the respondent is well aware of the notion of empowerment and ethical consumption. Thus, we will try to cross these questions relating to empowerment as well as ethical consumption with the income and level of education of the respondent. Subsequently, we will verify the underlying link between socio-cultural characteristics and the degree of consciousness that leads to empowerment. We will then be able to say whether Tunisians with a more favorable professional situation with a higher level of education are better able to be informed consumers and thereby better able to adopt and promote renewable energies even if it is necessary to pay a higher price (the notion of price tolerance). Next, we will focus on the role of the state and in particular on the legal framework. 
Thus, we will try to understand via our study, whether the State via its legal and regulatory system participates in helping the consumer to be more conscientious of his environment. The model takes into consideration the opinion of the Tunisian consumer because he is the center of interest of our work to identify his perspective and his vision of the legal situation and see, in the eyes of the Tunisian citizen, the efforts of the State and its regulations are sufficient or very little developed or unknown to the public. The results of our study will be important to help foreign partners who will be able to know if the Tunisian consumer is finally ready for the adoption of these energies and if so if the whole population is ready or just an elite. Also, the State will be able to know if its efforts are sufficient.

\subsection{Content Analysis: Data Encoding}

We considered 12 interviews since we start the research and we found that there's certain redundancy, and it is, therefore, necessary to interpret that it exists more or less convergence in the themes addressed. In the same vein, we will present some outputs (released) of the MAXQDA software as well as the R software. These will allow us to better understand the subject and emerge from qualitative conclusions. Thus, we carried out a thematic analysis by grouping all the terms belonging to the same idea or lexical fields. This grouping has allowed us to synthesize information to move from an unprecedented amount of information to very precise, clear, and concise axes. For each theme we used a color code, the major themes have been divided into several sub-themes to better understand the information and analyze it. We have included only the most important outputs for our analysis.

\subsection{Presentation of the Corpus}

All the words and expressions mentioned during the 12 interviews are equal to 7176 , as shown in the excerpt below.

\section{$\sum$ Word Frequency}

\section{In 12 Texts (7176 Words Total)}

\section{Lexical Analysis via MAXQDA and R Software}

The analysis allowed us to understand 8 main themes. The diagram below presents the different themes and sub-themes as well as their frequency of appearance:

Table 1. The different theme

\begin{tabular}{ll}
\hline Code & All Co \\
\hline The importance of RE & 35 \\
The empowerment of the Tunisian consumer & 29 \\
Level of Education & 28 \\
The rôle of the Government for the development & 27 \\
Law system & 26 \\
Boycott & 25 \\
Ethic Consumer & 23 \\
Tolerance of the price & 23 \\
\hline
\end{tabular}

Now we will highlight the frequency of each theme per interview: 
Table 2. Frequency of each theme per interview

\begin{tabular}{lllllllllllll}
\hline Code System & L11 & L12 & L10 & L9 & L8 & L7 & L6 & L5 & L4 & L3 & L2 & L1 \\
\hline $\begin{array}{l}\text { The empowerment of the } \\
\text { consumer }\end{array}$ & 6 & 3 & 3 & 2 & & & 5 & 3 & 2 & 2 & 1 & 2 \\
$\begin{array}{l}\text { Ethic Consumer } \\
\text { Role of the government }\end{array}$ & 3 & 1 & 1 & 2 & & 4 & 3 & 1 & 3 & 2 & 2 & 1 \\
Importance Of RE & 3 & 1 & & 1 & & 1 & 5 & 2 & 5 & 3 & 1 & 5 \\
LAW System & 4 & 3 & 1 & 1 & 2 & & 5 & 2 & 3 & 3 & 5 & 6 \\
Tolerance of price & 5 & 1 & 1 & 1 & 5 & 1 & 3 & 1 & 3 & 1 & 1 & 3 \\
Level of Education & 4 & 2 & 3 & 4 & 2 & 3 & 1 & 1 & & & 2 & 2 \\
Boycott & 4 & 1 & 3 & 2 & 1 & 5 & 2 & 2 & 2 & 2 & 2 & 2 \\
& 4 & 1 & 3 & 3 & 3 & 2 & 2 & 2 & 1 & 1 & 1 & 1 \\
\hline
\end{tabular}

Table 3. Frequency of each theme per interview by color

\begin{tabular}{|c|c|c|c|c|c|c|c|c|c|c|c|c|}
\hline Code System & L11 & L12 & L10 & L9 & L8 & L7 & L6 & L5 & $\mathbf{L 4}$ & $\mathbf{L 3}$ & $\mathbf{L 2}$ & L1 \\
\hline $\begin{array}{l}\text { The empowerment of the } \\
\text { consumer }\end{array}$ & 0 & - & 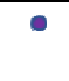 & - & & & - & $\bullet$ & 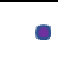 & - & . & $\bullet$ \\
\hline Ethic Consumer & $\mathbf{0}$ & - & - & - & & 0 & $\bullet$ & . & • & $\bullet$ & - & . \\
\hline Role of the government & 0 & • & & . & & . & - & - & $\bullet$ & $\bullet$ & . & $\bullet$ \\
\hline Importance Of RE & $\bullet$ & • & . & . & $\bullet$ & & $\bullet$ & • & • & $\bullet$ & - & - \\
\hline LAW System & $\bullet$ & • & . & . & - & . & - & . & • & . & . & $\bullet$ \\
\hline Tolerance of price & - & $\mathbf{a}$ & - & - & e & $\bullet$ & . & . & . & & & $\bullet$ \\
\hline Level of Education & $\bullet$ & . & - & • & & $\bullet$ & - & - & - & • & $\bullet$ & • \\
\hline Boycott & - & . & e & & cina & - & - & $\bullet$ & - & . & . & . \\
\hline
\end{tabular}

\subsection{Graphical Analysis}

The graphic analysis of the words most used by interview brings together the most frequent vocabulary per interview and puts in the middle the one that is frequent in all interviews:

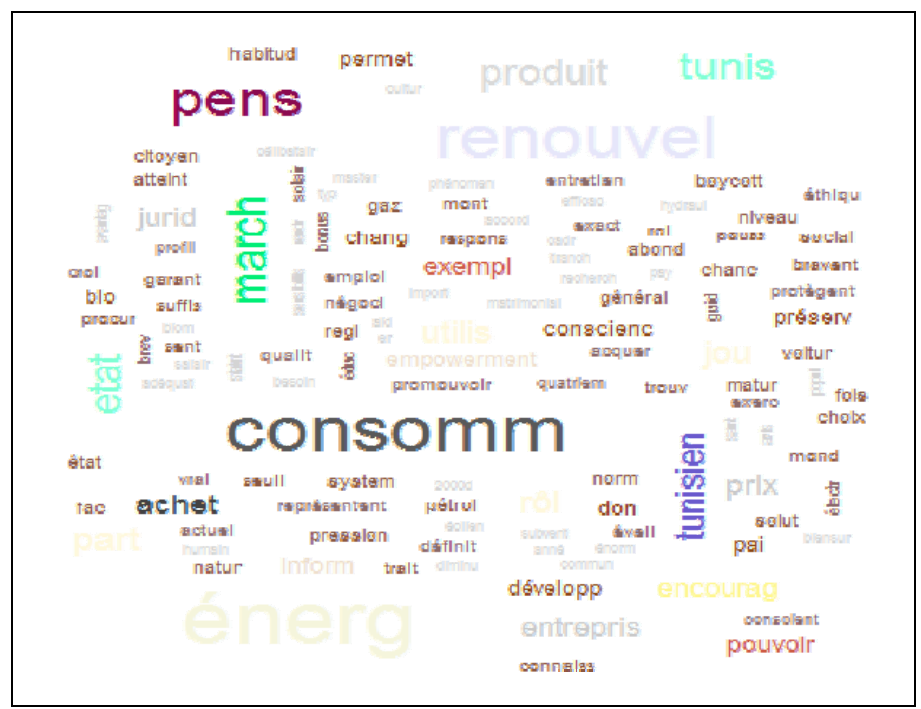

Figure 2. The most commonly used words

In addition, does this analysis carried out by the R software make it possible to identify the most used words in the entire space but also by interview. 


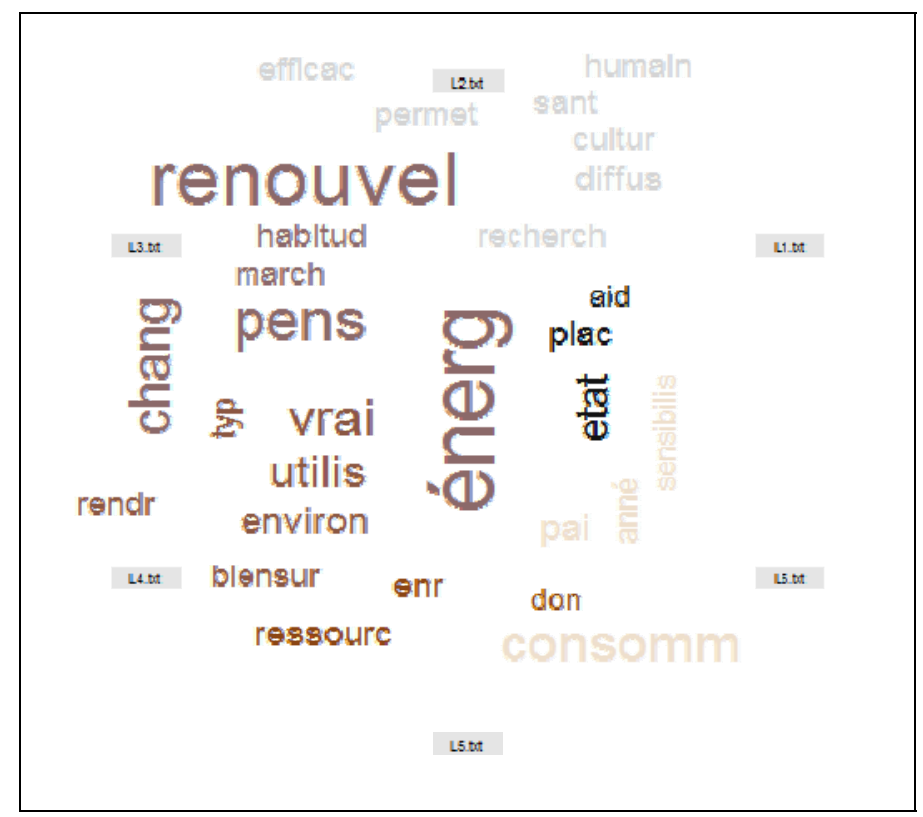

Figure 3. Words used by the interview

\subsection{Analysis of the Results}

Most respondents believe that the REC sector is becoming "vital" and "essential" for the economy in Tunisia. Through an "energy wealth", Tunisia must know how to exploit "its incredible potential of this energy", also, it is considered "a good solution against the rise in gas and oil prices". Indeed, according to the respondents, the State plays a "preponderant" role. Indeed, it must "punish" polluters and encourage with "subsidies" those who "invest in this sector". Also, it has a role in raising consumer awareness and stresses that the State's efforts remain insufficient. Even if the respondents think that the customer "is not yet king" they think that the Tunisian consumer has more and more value and becomes more and more the center of concern.

In addition, the Tunisian consumer thanks "Internet" and in particular the social networks "Facebook" and "Instagram" and feels the power to control things. Moreover, with the rise and awakening of consciousness, Tunisians are thinking more about fair trade and ethical consumption. Citizens want to "preserve the interests of the community", "save the planet", "consume with future generations in mind".

It is noted that the legal system remains in the eyes of consumers "insufficient" and must be more "encouraging" and «laxer» to encourage the renewable energy sector. Consumers think that the laws are there to help for the "use of EVs." We note that the majority of respondents agree to pay more for products with electronic vehicles EV such as the electric car.

We also notice that more and more Tunisians are imbued with the boycott culture and refuse corporate abuse. Regarding the level of education remains a very important point because our population has been chosen from a CSP A and B + with a university-level mostly with bachelor's degree and master's degree. The latter have met their basic needs and are starting to think about the planet's sustainable development and the green economy. Nevertheless, it may be assumed that categories CSP C and D do not have the same interests.

\section{Conclusion}

Our article highlights a current context of ambivalence, where the consumer shows that he is willing to pay more to acquire organic products and in particular with renewable energies but it depends on the level of education and the standard of living. De facto, we can ask ourselves if empowerment represents reality for consumers with the emergence of the Internet which plays a major role in the emergence of online communities, where people meet, discuss and exchange on communication platforms. Based on a literature review and a qualitative study, we considered how consumers perceive REC. However, this research is the first step towards a better understanding of consumer empowerment in the context of REC. This article is subject to several limits and obstacles including the technique of sampling by convenience which does not give any power of generalization for this work, the work has taken into consideration only the vision of the consumer without identifying the vision of NGOs, associations, and The State. 


\section{References}

Angelo, J. (2021). Relationship between real effective exchange rate and labor productivity: Empirical evidence. Management Science and Business Decisions, 1(1), 21-28. https://doi.org/10.52812/msbd.18

Arsy, F. A. (2021). Demand forecasting of Toyota Avanza cars in Indonesia: Grey Systems Approach. International Journal of Grey Systems, 1(1), 38-47. https://doi.org/10.52812/ijgs.24

Auger, P., Devinney, T. M., Louviere, J. J., \& Burke, P. F. (2008). Do social product features have value to consumers? International Journal of Research in Marketing, 25(3), $183-191$. https://doi.org/10.1016/j.ijresmar.2008.03.005

Boamah, V. (2021). Forecasting the demand of oil in Ghana: A statistical approach. Management Science and Business Decisions, 1(1), 29-43. https://doi.org/10.52812/msbd.25

Bourdieu, P. (2018). Distinction: A social critique of the judgment of taste*. Food and Culture, 141-150. https://doi.org/10.4324/9781315680347-10

Bowers, M. R., Martin, C. L., \& Luker, A. (1990). Trading places: Employees as customers, customers as employees. Journal of Services Marketing, 4(2), 55-69. https://doi.org/10.1108/eum0000000002512

Bradfield, M., Friedman, M., \& Friedman, R. (1982). Free to choose: A personal statement. Canadian Public Policy / Analyse De Politiques, 8(2), 265. https://doi.org/10.2307/3550171

Brown, S. (1995). Postmodern marketing research: No representation without taxation. Market Research Society Journal, 37(3), 1-21. https://doi.org/10.1177/147078539503700306

Clarke, G. (2006). 'The ethical consumer' edited by Rob Harrison, Terry Newholm and Deidre Shaw Sage, London, UK; 2005; ISBN: 141290353X; 259 pages. Journal of Consumer Behaviour, 5(1), 95-96. https://doi.org/10.1002/cb.36

Cochoy, F. (1998). Another discipline for the Market Economy: Marketing as a performative knowledge and know-how for capitalism. The Sociological Review, 46(1_suppl), 194-221. https://doi.org/10.1111/j.1467-954x.1998.tb03475.x

Csikszentmihalyi, M. (1999). If we are so rich, why aren’t we happy? American Psychologist, 54(10), 821-827. https://doi.org/10.1037/0003-066x.54.10.821

Danyel, R. (2002). Handbook of Renewable Energies in the European Union. New York. https://doi.org/10.3726/978-3-653-01905-6/13

Deshpandé, R. (2002). Performance companies. Journal of Medical Marketing, 2(3), $225-231$. https://doi.org/10.1057/palgrave.jmm.5040080

Devine-Wright, P. (2005). Beyond nimbyism: Towards an integrated framework for understanding public perceptions of wind energy. Wind Energy, 8(2), 125-139. https://doi.org/10.1002/we.124

Dholakia, N., Darmody, A., Zwick, D., Dholakia, R. R., \& Firat, A. F. (2020). Consumer choice-making and choicelessness in hyper-digital marketspaces. Journal of Macromarketing, 41(1), 65-74. https://doi.org/10.1177/0276146720978257

Diamantopoulos, A., Schlegelmilch, B. B., Sinkovics, R. R., \& Bohlen, G. M. (2003). Can socio-demographics still play a role in profiling green consumers? A review of the evidence and an empirical investigation. Journal of Business Research, 56(6), 465-480. https://doi.org/10.1016/s0148-2963(01)00241-7

Diener, E. (2000). Subjective well-being: The science of happiness and a proposal for a national index. American Psychologist, 55(1), 34-43. https://doi.org/10.1037/0003-066x.55.1.34

Doane, D. (2001). Taking Flight: The Rapid Growth of Ethical Consumerism. New Economics Foundation, London.

Dobson, A. (1998). Environmental politics and distributive justice. Justice and the Environment, 12-30. https://doi.org/10.1093/0198294956.003.0002

Goldsmith, E. B. (2005). Consumer empowerment: Public policy and insurance regulation. International Journal of Consumer Studies, 29(1), 86-92. https://doi.org/10.1111/j.1470-6431.2005.00384.x

Gritten, A. (2007). Forum-media proliferation and the demand for new forms of research. International Journal of Market Research, 49(1), 15-23. https://doi.org/10.1177/147078530704900105

Grolin, J. (1998). Corporate Legitimacy in Risk Society: The case of Brent Spar. Business Strategy and the 
Environment,

$7(4)$

$213-222$. https://doi.org/10.1002/(SICI)1099-0836(199809)7:4<213::AID-BSE158>3.0.CO;2-I

Handlin, O. (1963). Capitalism and freedom. by Milton Friedman with the assistance of Rose D. Friedman. Chicago, the University of Chicago Press, 1962. pp. VI + 202. \$3.95. Business History Review, 37(3), 315-316. https://doi.org/10.2307/3112263

Harrison, J. H. (2005). Information delivery methods. Health Informatics, 61-70. https://doi.org/10.1007/0-387-27652-1_5

Henry, P. C. (2005). Social class, market situation, and consumers' metaphors of (dis)empowerment. Journal of Consumer Research, 31(4), 766-778. https://doi.org/10.1086/426610

Holbrook, M. B., \& Hirschman, E. C. (1982). The experiential aspects of consumption: Consumer fantasies, feelings, and fun. Journal of Consumer Research, 9(2), 132. https://doi.org/10.1086/208906

Hubert, L. D., \& Paul, R. (1983). Michel Foucault: Beyond structuralism and hermeneutics (afterword by Michel Foucault). Chicago: University of Chicago Press. https://doi.org/10.7208/chicago/9780226154534.001.0001

Lang, T., \& Gabriel, Y. (n.d.). A brief history of consumer activism. The Ethical Consumer, 39-54. https://doi.org/10.4135/9781446211991.n4

Lincoln, N. D., Travers, C., Ackers, P., \& Wilkinson, A. (2002). The meaning of empowerment: The interdisciplinary etymology of a new management concept. International Journal of Management Reviews, 4(3), 271-290. https://doi.org/10.1111/1468-2370.00087

Lusch, R. F., \& Brown, J. R. (1996). Interdependency, contracting, and relational behavior in marketing channels. Journal of Marketing, 60(4), 19. https://doi.org/10.1177/002224299606000404

Lyubomirsky, S. (2006). Happiness: Lessons from a new science - R. Layard. The British Journal of Sociology, 57(3), 535-536. https://doi.org/10.1111/j.1468-4446.2006.00123_12.x

Mathur, N. (n.d.). Modernity, consumer culture and construction of Urban Youth Identity in India: A disembedding perspective. Consumer Culture, Modernity and Identity, 89-121. https://doi.org/10.4135/9789351507932.n4

Mock, M. (2000). Soaring into the next decade... planning for the future. Orthopaedic Nursing, 19(2), 14-15. https://doi.org/10.1097/00006416-200019020-00001

Mowitt, J., Morris, M., \& Patton, P. (1980). Michel Foucault: Power, truth, strategy. SubStance, 9(3), 93. https://doi.org/10.2307/3683911

Nawaz, M., Javed, S., Shah, S. M., Mustafa, M., Unsa, \& Namatullah, A. (2021). Conceptualizing supplier work passion in light of the Zigarmi's framework. Management Science and Business Decisions, 1(1), 44-51. https://doi.org/10.52812/msbd.7

Nicholls, A. J. (2002). Strategic options in fair trade retailing. International Journal of Retail \& Distribution Management, 30(1), 6-17. https://doi.org/10.1108/09590550210415220

Oswald, A. J. (1997). Happiness and Economic Performance. The Economic Journal, 107(445), $1815-1831$. https://doi.org/10.1111/j.1468-0297.1997.tb00085.x

Parasuraman, A., Berry, L. L., \& Zeithaml, V. A. (1991). Perceived service quality as a customer-based performance measure: An empirical examination of organizational barriers using an extended service quality model. Human Resource Management, 30(3), 335-364. https://doi.org/10.1002/hrm.3930300304

Paulin, M., Ferguson, R. J., \& Payaud, M. (2000). Business Effectiveness and professional service personnel relational or transactional managers? European Journal of Marketing, 34(3/4), 453-472. https://doi.org/10.1108/03090560010311966

Perkins, D. D., \& Zimmerman, M. A. (1995). Empowerment theory, research, and application. American Journal of Community Psychology, 23(5), 569-579. https://doi.org/10.1007/bf02506982

Pitt, L. F., Berthon, P. R., Watson, R. T., \& Zinkhan, G. M. (2002). The internet and the birth of real consumer power. Business Horizons, 45(4), 7-14. https://doi.org/10.1016/s0007-6813(02)00220-3

Samli, A. C. (2001). Empowering the American Consumer: Corporate Responsiveness and Market Profitability. Journal of Consumer Marketing, 19(2), 171-173. https://doi.org/10.5860/CHOICE.38-5112

Sargiacomo, M. (2009). Michel Foucault, Discipline and punish: The birth of the prison. Journal of Management \& Governance, 13(3), 269-280. https://doi.org/10.1007/s10997-008-9080-7 
Sawhney, M., \& Prandelli, E. (2000). Communities of Creation: Managing Distributed Innovation in turbulent markets. California Management Review, 42(4), 24-54. https://doi.org/10.2307/41166052

Schwartz, B. (2009). The Costs of Living: How Market Freedom Erodes the Best Things in Life.

Shaw, D., \& Clarke, I. (1999). Belief formation in ethical consumer groups: An exploratory study. Marketing Intelligence \& Planning, 17(2), 109-120. https://doi.org/10.1108/02634509910260968

Strong, C. (1996). Features contributing to the growth in ethical consumerism - a preliminary investigation. Marketing Intelligence \& Planning, 14(5), 5-13. https://doi.org/10.1108/02634509610127518

Thompson, C. J. (2003). Postmodern consumer goals made easy (pp. 120-139).

Umit, K. S. (2009). Consumer empowerment model: From unspeakable to undeniable. Direct Marketing: An International Journal, 3(4), 327-342. https://doi.org/10.1108/17505930911000892

Wathieu, L., Brenner, L., Carmon, Z., Chattopadhyay, A., Wertenbroch, K., Drolet, A., ... Wu, G. (2002). Consumer Control and Empowerment: A Primer. Marketing Letters, 13(3), 297-305. https://doi.org/10.1023/a:1020311914022

Werner, M. (1992). The great paradox: Responsibility without empowerment. Business Horizons, 35(5), 55-58. https://doi.org/10.1016/0007-6813(92)90054-d

Wilkinson, A. (1998). Empowerment: Theory and practice. Personnel Review, 27(1), 40-56. https://doi.org/10.1108/00483489810368549

Willmott, H. (n.d.). On the idolization of markets and the denigration of marketers: Some critical reflections on a professional paradox. Rethinking Marketing: Towards Critical Marketing Accountings, 205- 222. https://doi.org/10.4135/9781446280058.n15

Wind, J., \& Rangaswamy, A. (2001). Customization The next revolution in mass customization. Journal of Interactive Marketing, 15(1), 13-32. https://doi.org/10.1002/1520-6653(200124)15:1<13::AID-DIR1001>3.0.CO;2-\#

Yoga, I., \& Yudiarta, I. G. (2021). Grey forecasting of inbound tourism to Bali and financial losses from the COVID-19. International Journal of Grey Systems, 1(1), 48-57. https://doi.org/10.52812/ijgs.17

Zimmerman, M. A., \& Warschausky, S. (1998). Empowerment theory for rehabilitation research: Conceptual and methodological issues. Rehabilitation Psychology, 43(1), 3-16. https://doi.org/10.1037/0090-5550.43.1.3

\section{Copyrights}

Copyright for this article is retained by the author, with first publication rights granted to the journal.

This is an open-access article distributed under the terms and conditions of the Creative Commons Attribution license (http://creativecommons.org/licenses/by/4.0/). 